http://jmscr.igmpublication.org/home/ ISSN (e)-2347-176x ISSN (p) 2455-0450 crossref DOI: https://dx.doi.org/10.18535/jmscr/v7i8.58

\title{
Comparative Study of Laparoscopic Assisted Appendicectomy and Open Appendicectomy
}

\author{
Authors \\ Dr Kunal ${ }^{1}$, Dr Reyazuddin Ahmad ${ }^{2}$, Prof. (Dr) A.P. Singh ${ }^{3}$ \\ ${ }^{1}$ Associate Professor, Department of Surgery GMC, BETTIAH \\ ${ }^{2}$ Assistant Professor, Department of Surgery, GMC, BETTIAH \\ ${ }^{3}$ Professor, Department of Surgery, GMC, BETTIAH
}

\begin{abstract}
Background: Open Appendicectomy is less expensive and faster to perform but lacks the ability to visualize the whole peritoneal cavity. Laparoscopic appendicectomy is more expensive and time consuming as compared to open technique. On the other hand laparoscopic assisted appendicectomy has the advantages of both the open and laparoscopic methods.

Methods: This was a retrospective study of patients that underwent appendicectomy by open or lap assisted techniques.

Results: Total of 45 patients were selected for the study. Lap assisted appendicectomy was performed in 24 patients and open technique in 21 patients. The average operating time was 35 min for both lap assisted and open appendicectomy. Average Duration of stay was 1.8 days for lap assisted and 3 days for open technique. Conclusion: The Lap assisted technique can be performed as efficiently as open technique with advantages of lesser costs and short postoperative stay.

Keywords: Laparoscopic Assisted, appendicectomy, appendicitis.
\end{abstract}

\section{Introduction}

Appendicectomy is the most common emergency surgical procedure performed with the highest incidence in second and third decade of life. Charles McBurney in 1889 advocated early operative intervention for suspected acute appendicitis. Open appendicectomy through right lower quadrant muscle splitting incision became the standard operative procedure followed by laparoscopic technique in the next century. The first laparoscopic appendicectomy was reported by Semm in 1983. The laparoscopic approach is now the most common method used.

Laparoscopic appendicectomy is an intracorporeal operation and requires three or more ports, endoloop for mesoappendix and appendicular base, or expertise in intracorporeal ligation.

A technique to reduce operating room time and cost is a combination of the laparoscopic and open technique called the laparoscopic-assisted technique. Hence we adopted a laparoscopic assisted appendicectomy approach using two nondisposable ports to save the cost and with no added morbidity. Two port assisted open appendicectomy has the advantage of diagnostic laparoscopy and open appendicectomy. It is simple and can be converted to open or intracorporeal approach when required. It offers the advantages of both the laparoscopic and the open techniques with less postoperative pain, 
faster recovery, less costly and less operating time.

\section{Methods}

The study group consisted of 45 patients selected over a two and a half year period. The laparoscopic assisted technique involved 24 patients, the open technique 21 patients.

We conducted a study of two different methods for removing the appendix. The first method was the traditional open method involving a muscle splitting technique through a McBurney incision. The second method was the laparoscopic-assisted technique involving insufflation of the abdomen through an infraumbilical port. Laparoscopic approach was avoided in patients with multiple previous surgeries, contraindications for general or regional anesthesia. Majority of the patients were in younger age group and females. A routine work up included the blood count, urea, electrolyte, blood sugar, and urine examination. Pregnancy test, chest radiograph, abdominal radiograph, ultrasound were performed .CT scan was performed in few cases. Laparoscopy was performed within 48 hours of admission. Pneumoperitoneum was established by open method. Laparoscope was introduced through 10 $\mathrm{mm}$ umbilical port and the diagnosis was established. A 10-mm port was placed through the abdomen over the location of the appendix in right iliac fossa. A Babcock grasper was used to clamp the appendix that was then pulled within the trocar port; the air in the abdomen was removed, thus allowing the appendix to be pulled through the incision into the operating field. The mesoappendix was dissected and vessels were ligated as in the traditional open technique. The appendiceal stump was then ligated. Once the appendix was removed, the cecum and appendiceal stump were placed within the abdomen after touching it with Povidine-Iodine swab and also the port site. The abdomen was again insufflated to check for hemostasis and to irrigate the abdominal cavity. Thorough peritoneal lavage was performed in all cases of peritonitis.
When required, the right iliac fossa port was used for inserting the intraabdominal drain The trocars were removed and the fascia and peritoneum were closed.

\section{Results}

Forty five appendicectomies were performed in 14 males and 31 females. The mean age of the study population was 27.7 \pm 9.7years. Lap assisted appendicectomy was performed in 24 patients and open technique in 21 patients. There was no mortality from this procedure. The mean operating time was 35 minutes both for lap assisted appendicectomy and open appendicectomy. The two port lap appendicectomy was successful in $87.5 \%(n=24)$.A total $12.5 \%(n=3)$ were converted to open appendicectomy. The incidence of perforated/gangrenous appendix was $4.16 \%(\mathrm{n}=1)$, inflamed appendix $70.8 \%(\mathrm{n}=17)$, appendicular mass/abscess $8.33 \%(\mathrm{n}=2)$, and appendix looked normal laparoscopically in $16.6 \% \quad(n=4)$. Complications of lap assisted appendicectomy were port site infection $(n=2)$, pain $(n=3)$, intra abdominal abscess $(n=1)$. Complications of open appendicectomy were surgical site infection $(n=4)$ and pain $(n=5)$. There was no case of appendicular tumor reported in histopathology in this series. Abdominal drain was used in $20.8 \% \quad(n=5)$ of patients. The appendicectomy was performed between 4-48 hours of admission. The mean hospital stay was 1.8 days for lap assisted appendicectomy and 3days for open appendicectomy.

\section{Table 1}

\begin{tabular}{|l|c|}
\hline Total no. of patients & $\begin{array}{c}45 \\
\text { Males- } 14 \\
\text { Females-31 }\end{array}$ \\
\hline Age & $27.7 \pm 9.7$ years \\
\hline Lap assisted appendicectomy & $24(\mathrm{M}=5, \mathrm{~F}=19)$ \\
\hline Open appendicectomy & $21(\mathrm{M}=9, \mathrm{~F}=12)$ \\
\hline
\end{tabular}

Table 2

\begin{tabular}{|l|c|c|}
\hline & $\begin{array}{c}\text { Mean Operating } \\
\text { Time(min) }\end{array}$ & $\begin{array}{c}\text { Mean Duration } \\
\text { Of Stay(hours) }\end{array}$ \\
\hline $\begin{array}{l}\text { LAP ASSISTED } \\
\text { APPENDICECTOMY }\end{array}$ & 35 & 43.2 \\
\hline $\begin{array}{l}\text { OPEN } \\
\text { APPENDICECTOMY }\end{array}$ & 35 & 72 \\
\hline
\end{tabular}


Table 3: Indications for conversion to open technique

\begin{tabular}{|l|c|}
\hline Indication & No. of patients \\
\hline Appendicular mass/abscess & 3 \\
\hline Perforated/Gangrenous appendix & 1 \\
\hline
\end{tabular}

Table 4: Complications Lap Assisted Appendicectomy:

\begin{tabular}{|l|c|}
\hline Complications & No. of patients \\
\hline Port site Infection & $2(9.52 \%)$ \\
\hline Port site pain & $3(14.2 \%)$ \\
\hline Intra abdominal abscess & $1(4.7 \%)$ \\
\hline
\end{tabular}

Open Appendicectomy:

\begin{tabular}{|l|c|}
\hline Complications & No. of patients \\
\hline Surgical site infection & $4(19.04 \%)$ \\
\hline Pain & $5(23.8 \%)$ \\
\hline
\end{tabular}

\section{Discussion}

Lap assisted appendicectomy can be performed in same operative time as compared to open appendicectomy (35min). Moreover the hospital duration of stay is less with lap assisted appendicectomy (1.8days) as compared to open appendicectomy (3 days). There are fewer complications with less morbidity than open appendicectomy.

\section{Conclusion}

The introduction of laparoscopic surgery has had a great impact in many areas of general surgery. Laparoscopic appendicectomy has not been accepted by surgeons as quickly because of the longer operating time and greater cost of the laparoscopic technique when compared with the open technique. However, patients suffer less postoperative pain and have shorter hospital stays with the laparoscopic technique when compared with the open technique. The laparoscopicassisted technique has an advantage over the open technique in that it can be utilized as a diagnostic tool. The laparoscopic-assisted method is initially used to visualize the appendix, and thus diagnose appendicitis. If the cause of the abdominal pain is not appendicitis, the abdomen can be further explored laparoscopically to assess for another cause of abdominal pain without the use of any radiologic tests. If during an open appendectomy, the appendix appears normal, the abdominal exploration is more difficult to perform and, therefore, it is more difficult to determine the cause of the abdominal pain. In fact, the operation may even require a larger incision prolonging the operating time. In atypical presentation of appendicitis, diagnostic radiologic studies such as ultrasound and CT scan have a relatively high degree of accuracy, but not as great as direct visualization with the laparoscope. The two port laparoscopic assisted open apendicectomy is simple, easy to learn. It can be converted to open appendicectomy very quickly when required or to total intracorporeal approach by inserting accessory ports. The Lap assisted technique provides a laparoscopic method that can be performed in same amount of operating time as an open technique. The surgical expense of a laparoscopic-assisted procedure is close to the surgical cost of an open procedure. Patients undergoing the Lap Assisted Appendicectomy technique appear to have the advantage of reduced postoperative recovery stay as Open Appendicectomy patients (1.8 days vs. 3 days).

\section{References}

1. Comparison of Laparoscopic-Assisted Appendectomy with Intracorporal Laparoscopic Appendectomy and Open Appendectomy, Thomas Nicholson, MD and Vasudevan Tiruchelvam, MD

2. Laparoscopically Assisted Appendicectomy in Adults: A comparative analysis Misauno M.A., Isichei M.W., ALE A.F. IOSR Journal of Dental and Medical Sciences (IOSR-JDMS) e-ISSN: 2279-0853, p-ISSN: 2279-0861. Volume 8, Issue 3 (Jul.- Aug. 2013), PP 24-27

3. Laparoscopic Assisted Two Port Open Appendicectomy, Vishwanath Golash From the Department of Surgery, Sultan Qaboos Hospital, Salalah, Governerate of Dhofar, Sultanate of Oman.

4. Golash V, Willson PD, early laparoscopy as a routine procedure in the management 
of acute abdominal pain: A review of 1320 patients. Surg Endosc 2005; 19:882-885.

5. Golash V. Rectus sheath abscess after laparoscopic appendicectomy. J Min Access Surg 2008; 3:64-65.

6. Konstadoulakis MM, Gomatos IP, Antonakis PT, Manouras A, Albanopoulos $\mathrm{K}$, Nikiteas $\mathrm{N}$, et al. Two trocar laparoscopic assisted appendectomy versus conventional laparoscopic appendectomy in patients with acute appendicitis. J Laparoendosc Adv Surg Tech A. 2006; 16:27-32.

7. Fazili FM, Al-Bouq Y, El-Hassan OM, Gaffar HF. Laparoscopic-assisted appendicectomy in adults: the two trocar technique. Ann Saudi Med. 2006; 26:100104.

8. Ahmet Tekin H. Cemal Kurtoğlu. VideoAssisted Extracorporeal Appendectomy Journal of Laparoendoscopic \& Advanced Surgical Techniques. 2002; 12:57-60

9. Katkhouda N, Mason RJ, Towfigh S, Gevorgyan A, Essani R. Laparoscopic versus open appendectomy: a prospective randomized double-blind study. Ann Surg. 2005 Sep;242(3):439-48.

10. Kazemier G, de Zeeuw GR, Lange JF, Hop WC, Bonjer HJ. Laparoscopic vs open appendectomy. A randomized clinical trial. Surg Endosc. 1997 Apr;11(4):336-40.

11. Malik AM, Talpur AH, Laghari AA. Video-assisted laparoscopic extracorporeal appendectomy versus open appendectomy. J Laparoendosc Adv Surg Tech A. 2009 Jun;19(3):355-9

12. Moazzez A, Mason RJ, Katkhouda N. Laparoscopic appendectomy: new concepts. World J Surg. 2011 Jul;35 (7):1515-8
13. Nicholson T, Tiruchelvam V. Comparison of laparoscopic-assisted appendectomy with intracorporal laparoscopic appendectomy and open appendectomy. JSLS. 2001 Jan-Mar;5(1):47-51

14. Yagnik VD, Rathod JB, Phatak AG. A retrospective study of two-port appendectomy and its comparison with open appendectomy and three-port appendectomy. Saudi J Gastroenterol. 2010 Oct-Dec;16(4):268-71. 